\title{
Factors related to the intention to leave and the decision to resign among newly graduated nurses: a complete survey in a selected prefecture in Japan
}

\author{
Maki Tei-Tominaga
}

Received: 9 March 2012/ Accepted: 6 November 2012/Published online: 30 November 2012

(C) The Japanese Society for Hygiene 2012

\begin{abstract}
Objective This study examined factors related to the intention to leave and the decision to resign, including individual and psychosocial factors in the work environment, among newly graduated nurses (NGNs).

Methods We distributed an anonymous self-administered questionnaire to all NGNs $(n=1,477)$ in a selected prefecture in Japan. The response rate was $41 \%$. We used completed female data $(n=493)$ for analysis. The questionnaire included a scale of the intention to leave, an item related to the decision to resign, psychosocial factors in the work environment (e.g., the Japanese short version of the Copenhagen Psychosocial Questionnaire, social support, presence of a role model), and individual factors (e.g., psychological distress, cumulative fatigue, job readiness) along with control variables.

Results The results of multivariate logistic regression analysis showed that the presence of a role model coincided with the upper quartile of the intention to leave and the decision to resign. Support from supervisors and job readiness showed significant relationships with the upper quartile of the intention to leave; those who received a hospital scholarship showed a significant relationship with the decision to resign. Additionally, psychological distress, inadequate break facilities, and an insufficient amount of permitted rest time were risk factors for the decision to resign, and cumulative fatigue was a risk factor for the upper quartile of the intention to leave.

Conclusions Our findings suggest that, while investment in facilities and human capital may have short-term
\end{abstract}

M. Tei-Tominaga $(\bowtie)$

Department of Nursing, Hyogo University of Health Sciences,

1-3-6 Minatojima, Chuo-ku, Kobe 650-8530, Japan

e-mail: temakimaki@huhs.ac.jp benefits, measures from a long-term perspective are needed for the prevention of future resignations among NGNs.

Keywords Decision to resign - Intention to leave . Newly graduated nurses · Copenhagen Psychosocial Questionnaire · Emotional labor

\section{Introduction}

Japan has the highest life expectancy in the world, resulting in a rapidly growing and aging society [1]. This increases medical costs and demands for more medical staff, including nurses. The Ministry of Health, Labor, and Welfare in Japan estimates that the demand for nurses is outstripping the supply, and that this will continue until at least 2015 [2]. The retention of newly graduated nurses (NGNs) is essential in order to sustain high-quality patient care in the future [3].

A high turnover of nurses negatively impacts a hospital's budget because of increased overheads. The turnover of nurses is unsustainable, assuming a mean turnover cost of $100 \%$ of the individual nurse's salary [4]. A rise in the early resignation of NGNs who received in-house efficiency training escalates this situation [5]. Therefore, the imperative for healthcare organizations in Japan to invest in measures to prevent early resignation among nurses is particularly salient.

A survey of the Japanese Nursing Association found that issues relating to the work environment (e.g., workplace relationships, difficulty of taking days off, dissatisfaction with nursing work) and individual reasons (e.g., educational advancement, change of their interest to another field, marriage, having a baby and raising children, health problems) were major factors of NGNs leaving their first 
position [6]. When employees resign for personal reasons, managers and supervisors are limited practically and ethically from intervening. However, when such decisions are based on work conditions and organizational culture, managers and supervisors can intervene [7]. This underscores the importance of hospital managers and supervisors understanding both individual factors (e.g., health reasons) and factors in the work environment before deciding whether and how best to intervene in the early resignation of NGNs.

A previous study of NGN turnover revealed that negative issues in the work environment (e.g., lack of support and guidance) were the main reasons NGNs left during their first year after graduation [8]. In addition, a lack of support from peers at work was an important factor related to actual turnover of NGNs $[9,10]$. Intention to leave is consistently the best predictor of actual employee turnover [7, 11]. This is supported by a previous study of NGNs revealing that those who left their job showed higher intention-to-leave scores than those who remained [12].

Previous studies of NGNs' intention to leave in Japan [13-15] examined the effect of psychosocial factors in the work environment using theory-based models (the demand-control model [16] and effort-reward imbalance (ERI) model [17]). These studies revealed psychosocial factors including high psychological job demands [15], poor supervisor support [13, 15], high effort [14], and low control and coworker support [13] to be associated with intention to leave among NGNs.

Differences in psychosocial factors in the work environment in previous studies related to NGN turnover, and their intention to leave may have been due to differences in methodology. These studies did not examine intention to leave and decision to resign using identical measures for all individuals. However, differences may also have been due to additional specific factors in the work environment influencing each outcome (the intention to leave and decision to resign) in the same individuals.

Some studies of job turnover in NGNs $[9,10]$ did not examine critical variables in the work environment (e.g., job demands). Other studies of NGNs' intention to leave [13-15] that have measured theory-based psychosocial factors have some disadvantages. Regarding the demandcontrol model, researchers have been critical of the demand dimension because it focuses primarily on task completion and quantitative demand. It is necessary to broaden the perspective of the job demands dimension in healthcare work [18]. In the ERI model, researchers concluded that it might be desirable to split up specific demands for some occupations based on effort (e.g., job demands) [19].

Given this background, further studies examining specific aspects of psychosocial factors in the NGNs' work environment (e.g., emotional demands in human service settings) are needed. In her book, The Managed Heart: Commercialization of Human Feeling, Hochschild [20] coined the expression "emotional labor," detailing the organizational control over service workers' emotional life at work. Emotional labor is typified by emotional demands, and has been recognized as an appreciable aspect of work involving direct interactions with clients and customers (e.g., human service work such as work of flight attendants and nurses) [20]. For effective service and greater profits, organizations can direct the process of interpersonal transactions between their workers and customers by adopting display rules that dictate the expression of certain emotions accompanying specific situations [21]. Accordingly, a study of nurses revealed that emotional demands derived from emotional labor were associated with nurses' intention to leave [22].

To take effective countermeasures against early resignation among NGNs, hospital managers and supervisors need to understand factors related to both the intention to leave and the decision to resign. Thus, the purpose of this study is to examine factors related to the intention to leave and the decision to resign among NGNs. These included individual and psychosocial factors in the work environment. As the demand for nurses increases in Japan, this study can provide hospital managers and supervisors valuable insight into possible countermeasures against the shortage of nurses.

\section{Methods}

\section{Ethical considerations}

Approval for this study was obtained from the institutional ethics committee at the author's institution (\#08015). All NGNs in this survey were not required to sign consent forms as return of the questionnaire constituted implied consent. Participants were informed about the voluntary nature of participation and assured of confidentiality in the handling of data.

\section{Participants and data collection}

We defined NGNs as nurses who did not have any nursing work experience after graduating from a nursing program. "Early resignation" was defined as nurses leaving their first job at a medical institution within 1 year after starting work.

Nursing shortages threaten the existence of hospitals and negatively influence the quality of local healthcare services. However, past studies in Japan of turnover and the intention to leave involved large advanced treatment hospitals or university hospitals with more than 500 beds 
[9, 10, 13-15]. In this study, we conducted a complete survey in a selected prefecture with a population of more than 5,000,000. This prefecture ranked among the top five prefectures in Japan in terms of high turnover of NGNs in 2007 and 2009 [23, 24].

We distributed the questionnaire to all NGNs in all hospitals $(n=353)$ in the selected prefecture in late December 2009. About $39 \%$ had more than 200 beds, and $15 \%$ were public hospitals. The person in charge of the nursing department in each hospital provided information about the study to potential participants. If NGNs agreed to participate, they completed and returned their questionnaire within 1-3 weeks of distribution. No reminder was sent to the participants after the first notice of the study.

Out of 1,477 NGNs, 600 (41\%) returned their completed questionnaire. Ninety-three percent $(n=559)$ were female, and $8 \%(n=41)$ male. We conducted statistical analyses using variables not adjusted for gender but stratified by gender because previous studies had shown that men and women differ substantially in their response to work-related stress [25] and on mental health scales [26]. Hence, after eliminating data from males and those with incomplete data, including missing or incomplete answers $(n=66)$, we used completed female data $(n=493)$ for analysis.

\section{Model for investigation}

As a model for investigation, we reviewed previous studies of NGNs that examined factors influencing turnover and the intention to leave $[9,10,12-15,27,28]$. We adapted our model, focusing on variables of individual factors and psychosocial factors in the work environment that could influence the two outcomes (the intention to leave and the decision to resign) as well as individual, employment, and organizational characteristics (Fig. 1).

\section{Measures}

The questionnaire items addressed individual attributes (sex, age, marital status, educational level), employment characteristics (receiving a hospital scholarship [27], desired position [9, 12], working hours [28], break facilities and amount of permitted rest time [28]), and organizational characteristics (hospital size [13], hospital type [28], basic charge for hospitalization [10]) as control variables based on the findings of other studies of the intention to leave and turnover among NGNs. As independent variables, the questionnaire assessed individual factors (job readiness, psychological distress, and cumulative fatigue [13-15]) along with psychosocial factors in the work environment (e.g., social support $[9,10,12,15]$ and the presence of a role model [14]).

While psychological job demand (e.g., effort) was an important factor of the intention to leave among NGNs [14], additional specific factors in the work environment, including emotional demands derived from emotional labor, have been shown to be associated with the intention to leave among nurses [22]. Since NGNs do not have
Fig. 1 Model for investigation. We adapted our model focusing on variables (individual factors, psychosocial factors in the work environment and individual attributes, as well as employment and organizational characteristics) that may influence the two outcomes (the intention to leave and the decision to resign)

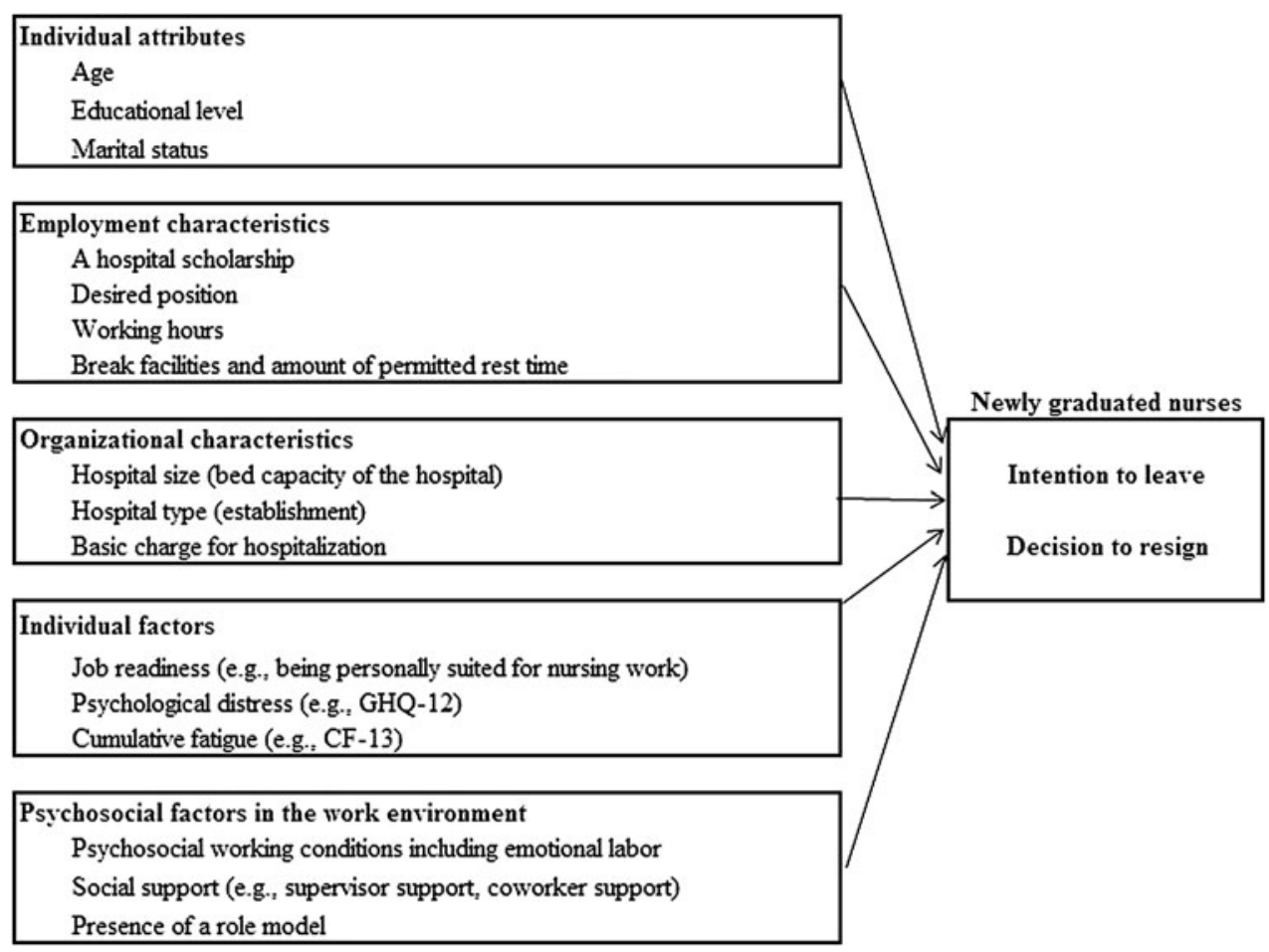


enough experience as nursing specialists, emotional demands may affect their intention to leave and decision to resign. Thus, the questionnaire also assessed psychological working conditions (including emotional labor) as psychosocial factors in the work environment.

Individual factors

\section{Job readiness (being personally suited for nursing work)}

Prior studies of NGNs in advanced treatment hospitals in Japan revealed that readiness, which implies the clinical, professional, and interpersonal skills and knowledge nurses need when they start to work, were important factors of the intention to leave. Additionally, in the 21-item Job Readiness Scale, one subscale, "being personally suited for nursing work," was consistently ranked as the most important factor of the intention to leave among NGNs [13-15]. Thus, we used three items regarding personal suitability for nursing work, which showed high reliability and face validity among Japanese NGNs [13-15]. Each item was evaluated using Likert-type scoring, ranging from 1 (least job readiness) to 4 (most job readiness). Higher total scores indicated greater job readiness, meaning NGNs felt personally suited for nursing work.

\section{Psychological distress}

We also used psychological distress as an indicator of subjective health status (individual factor). Psychological distress was assessed using the Japanese version of the 12-item General Health Questionnaire (GHQ-12), which has demonstrated high concurrent validity, internal consistency [29], and reliability in Japanese NGNs [13-15]. Participants were asked whether they had recently experienced particular symptoms or behavior related to depression or anxiety. The GHQ-12 items were scored using a Likert scale (1-4) to assess impairment level. Higher total scores indicated greater psychological distress.

\section{Cumulative fatigue}

We used cumulative fatigue as one sign of subjective health status (individual factor). The cumulative fatigue of participants was assessed using the 13-item Cumulative Fatigue Index (CF-13), a validated index developed by the Japanese Ministry of Health, Labor, and Welfare as a self-checklist of work-related fatigue accumulation [30]. Participants were asked whether they had recently experienced specific symptoms related to cumulative fatigue. Responses were scored with a three-point Likert scale. Higher total scores indicated more cumulative fatigue symptoms.
Psychosocial factors in the work environment

\section{Psychosocial working conditions including emotional labor}

We assessed the psychosocial work environment using the Japanese short version of the Copenhagen Psychosocial Questionnaire (COPSOQ). This instrument was developed by Kristensen for the comprehensive assessment of psychological working conditions, including emotional labor [31, 32].

The COPSOQ has high internal reliability and validity for a range of working populations [31, 33]. The Japanese version of the COPSOQ was developed by the translation and back-translation procedure, and comprises five subscales: quantitative demands (seven items, e.g., "Do you have to work very fast?"), cognitive demands (eight items, e.g., "Does your work require that you remember a lot of things?"), emotional demands (three items, e.g., "Is your work emotionally demanding?"), demands for hiding emotions (two items, e.g., "Does your work require that you hide your feelings?"), and sensorial demands (five items, e.g., "Does your work require a high level of precision?") [32]. Scores for subscales of the COPSOQ are obtained by adding points for the individual questions, giving equal weight to each question. The questions have five response options, and the weights are $0,25,50,75$, and 100. The scale value is calculated as the simple average, and all scales ranged from 0 to 100 in this study population. The higher the total score, the greater the participant's perceived job demands.

\section{Social support}

Support from supervisors and coworkers are important factors related to NGNs' intention to leave [9, 10, 13, 15, 34]. We used the two subscales of the Social Support Scale in a 57-item simplified work-related stress questionnaire developed by Shimomitsu [35], which have shown high reliability and face validity among about 12,000 Japanese workers [36]. Participants were asked about frequency of social support from supervisors and coworkers on a fourpoint Likert scale ranging from 1 (not often) to 4 (very often). The combined scores of the four items were used. A higher total score indicated greater social support.

Presence of a role model

Senior nurses, including preceptors, play an important role as educators of NGNs [37]. A significant relationship between lack of a role model and NGNs' intention to leave was shown in a previous study, suggesting that future studies should take into account the effect of role models 
[14]. Thus, to assess the presence and influence of role models on NGNs, we used one item ("There is a nurse I work with who represents a professional ideal for me") that was evaluated using a four-point Likert scale. We used binary data for the presence of a role model with the answers "agree" and "totally agree" as 1 and answers "disagree" and "totally disagree" as 0 in the analysis.

Intention to leave

Beecroft et al. [12] estimated that $26 \%$ of NGNs who showed the intention to leave at 6 months after starting their career resigned from their hospital within 24 months. In the present study, the intention to leave was assessed using a six-item scale developed by Tei and Yamazaki [38], which showed high internal consistency, reliability, and validity for Japanese information technology service workers and NGNs [13-15, 38, 39]. Each item asks about participants' thoughts or behaviors related to job resignation. Responses are scored on a four-point Likert scale with higher total scores representing greater intention to leave. NGNs with a score in the upper quartile of the intention to leave were defined as a group at high risk for intention to leave.

\section{Decision to resign}

According to a study of nurses, the final decision to resign is usually made within 6 months prior to departure among $83 \%$ of all actual resignees [40]. We assessed the decision to resign using one item, "Will you resign from your current organization within this fiscal year (within 3 months)?" We used binary data for the decision to resign, with "yes" as 1 and "no" as 0 in the analysis.

\section{Data analysis}

We calculated descriptive statistics for individual, employment, and organizational characteristics of the sample. Next, we calculated descriptive statistics and Cronbach's alpha coefficients of dependent and independent variables. As preliminary analysis to identify the primary variables for multivariate logistic regression analysis, we examined coefficients of association between the two dependent variables (the upper quartile of the intention to leave and the decision to resign) and the nominal data of each variable (individual, employment, and organizational characteristics, and individual factors). Next, we conducted $t$ test for the mean comparisons of independent variables between two groups of each dependent variable. Finally, we performed multivariate logistic regression analysis for dependent variables (the upper quartile of the intention to leave and the decision to resign).
All independent variables (individual factors and psychosocial factors in the work environment) were entered into the equation along with variables of individual attributes, employment, and organizational characteristics. These were selected based on the results of preliminary analysis and entered into the equation using a stepwise method (backward selection method). The odds ratio (OR) and $95 \%$ confidence intervals for each control and independent variable were calculated for each dependent variable. All statistical analyses were performed with SPSS 15.0 (Tokyo, Japan). A $P$ value of less than 0.05 was regarded as indicating statistical significance.

\section{Results}

The average age of the 493 females was 23.92 years ( $\mathrm{SD}=4.59$ years). A summary of individual, employment, and organizational characteristics of the sample is presented in Table 1. Nineteen percent of participants had at least a university degree (or higher) in nursing, and $92 \%$ were single. Thirty-two percent received a scholarship from a current hospital, and $41 \%$ worked more than $51 \mathrm{~h}$ a week, which entailed more than $44 \mathrm{~h}$ of overtime work on a monthly basis. Although not specified in the table, all alpha coefficients of dependent variables and the intention to leave score were above 0.70 , except for one subscale of the COPSOQ (demands of hiding emotions, $\alpha=0.61$ ).

It should be noted that $7 \%(n=33)$ of the participants answered "I will resign from my current job within this fiscal year (within 3 months)" (Table 2). Results of coefficients of association for the dependent variables, break facilities and amount of permitted rest time in the hospital, basic charge for hospitalization, and presence of a role model showed significant relationships with both dependent variables (e.g., low risk/high risk group of the intention to leave, and yes/no group of the decision to resign). As shown in Table 3, all independent variables showed significant differences between the highrisk group and low-risk group of the intention to leave, while two independent variables (cognitive demands, emotional demands) showed significant differences between the "yes" group and "no" group for decision to resign.

Results of multiple logistic regression analysis for the upper quartile of intention to leave group (Table 4) showed that the upper quartile of intention to leave was significantly related to the following variables: being personally suited for nursing work $(\mathrm{OR}=0.661)$, cumulative fatigue $(\mathrm{OR}=1.112)$, supervisor support $(\mathrm{OR}=0.824)$, and lack of a role model $(\mathrm{OR}=3.932)$. Results of multiple logistic regression analysis for the decision to resign (Table 5) 
Table 1 Individual attributes and employment and organizational characteristics of the sample $(n=493)$

Variable

n

Individual attributes

1. Marital status

Single

452

Married

2. Education

Junior college or vocational school equivalent degree

397

81

College graduate or higher

Employment characteristics

3. Hospital scholarship

Received

Not received

4. Desirable position (in a word)

Yes

No

5. Average working hours per week

$\leq 40$

41-45

8

46-50

51-55

$56-60$

$61-65$

$\geq 66$

6. Average hours of overtime work on a monthly basis

$<44$

$\geq 45$

7. Frequency of working on days off per month

None

1-2 days per month

3-4 days per month

5 or more days per month

8. Break facilities and amount of permitted rest time in the hospital Appropriate

Not appropriate

Organizational characteristics

9. Hospital size (bed capacity of the hospital)

Fewer than 199 beds

200-399 beds

More than 400 beds

10. Hospital type (establishment)

University hospital

17

Public hospital

Private hospital or other

11. Basic charge for hospitalization

Ratio of the number of patient to that of nurses is $7: 1$

showed that the following variables were significantly associated with the decision to resign: not receiving a hospital scholarship $(\mathrm{OR}=3.238)$, inadequate break facilities and an insufficient amount of permitted rest time in the hospital $(\mathrm{OR}=3.232)$, psychological distress $(\mathrm{OR}=1.175)$, and lack of a role model $(\mathrm{OR}=2.794)$. 
Table 2 Coefficients of association results for the dependent variables $(n=493)$

\begin{tabular}{|c|c|c|c|c|c|c|c|c|}
\hline \multirow[t]{2}{*}{ Variable } & \multicolumn{4}{|c|}{ Intention to leave ${ }^{\mathrm{a}}$} & \multicolumn{4}{|c|}{ Decision to resign $^{\mathrm{b}}$} \\
\hline & $\begin{array}{l}\text { Low risk } \\
(n=345)\end{array}$ & $\begin{array}{l}\text { High risk } \\
(n=148)\end{array}$ & $\begin{array}{l}\text { Coefficient } \\
\text { of association }\end{array}$ & $P$ value & $\begin{array}{l}\text { No } \\
(n=460)\end{array}$ & $\begin{array}{l}\text { Yes } \\
(n=33)\end{array}$ & $\begin{array}{l}\text { Coefficient } \\
\text { of association }\end{array}$ & $P$ value \\
\hline \multicolumn{9}{|l|}{ Individual characteristics } \\
\hline \multicolumn{9}{|l|}{ 1. Age (years) } \\
\hline$<30$ & 316 & 127 & $0.087^{\mathrm{c}}$ & 0.051 & 415 & 28 & $0.044^{\mathrm{c}}$ & 0.323 \\
\hline$\geq 30$ & 29 & 21 & & & 45 & 5 & & \\
\hline \multicolumn{9}{|l|}{ 2. Marital status } \\
\hline Single & 24 & 17 & $-0.075^{\mathrm{c}}$ & 0.095 & 424 & 28 & $-0.066^{\mathrm{c}}$ & 0.141 \\
\hline Married & 321 & 131 & & & 36 & 5 & & \\
\hline \multicolumn{9}{|l|}{ 3. Education } \\
\hline $\begin{array}{l}\text { Junior college or vocational school } \\
\text { equivalent degree }\end{array}$ & 274 & 123 & $-0.043^{\mathrm{c}}$ & 0.343 & 372 & 25 & $0.032^{\mathrm{c}}$ & 0.474 \\
\hline University graduate or higher & 71 & 25 & & & 88 & 8 & & \\
\hline \multicolumn{9}{|l|}{ Employment characteristics } \\
\hline \multicolumn{9}{|l|}{ 4. Hospital scholarship } \\
\hline Received & 110 & 49 & $0.012^{\mathrm{c}}$ & 0.789 & 154 & 5 & $-0.098^{\mathrm{c}}$ & 0.030 \\
\hline Not received & 235 & 99 & & & 306 & 28 & & \\
\hline \multicolumn{9}{|l|}{ 5. Desirable position (in a word) } \\
\hline Yes & 210 & 76 & $0.088^{c}$ & 0.049 & 267 & 19 & $-0.002^{c}$ & 0.958 \\
\hline No & 135 & 72 & & & 193 & 14 & & \\
\hline \multicolumn{9}{|l|}{ 6. Average working hours per week } \\
\hline Less than $55 \mathrm{~h}$ & 217 & 72 & $0.133^{\mathrm{c}}$ & 0.003 & 268 & 21 & $-0.027^{\mathrm{c}}$ & 0.545 \\
\hline $56 \mathrm{~h}$ or more & 128 & 76 & & & 192 & 12 & & \\
\hline \multicolumn{9}{|c|}{ 7. Frequency of working on days off per month } \\
\hline None & 268 & 106 & $0.065^{\mathrm{c}}$ & 0.149 & 353 & 21 & $0.077^{\mathrm{c}}$ & 0.089 \\
\hline 1 or more days per month & 77 & 42 & & & 107 & 12 & & \\
\hline \multicolumn{9}{|c|}{ 8. Break facilities and amount of permitted rest time in the hospital } \\
\hline Adequate and sufficient & 245 & 66 & $-0.251^{\mathrm{c}}$ & $<0.001$ & 301 & 10 & $-0.182^{\mathrm{c}}$ & $<0.001$ \\
\hline Inadequate and insufficient & 100 & 82 & & & 159 & 23 & & \\
\hline \multicolumn{9}{|l|}{ Organizational characteristics } \\
\hline \multicolumn{9}{|c|}{ 9. Hospital size (bed capacity of the hospital) } \\
\hline Fewer than 199 beds & 36 & 15 & $0.034^{\mathrm{d}}$ & 0.757 & 46 & 5 & $0.682^{\mathrm{d}}$ & 0.317 \\
\hline 200-399 beds & 130 & 61 & & & 182 & 9 & & \\
\hline More than 400 beds & 179 & 72 & & & 232 & 19 & & \\
\hline \multicolumn{9}{|l|}{ 10. Hospital type (establishment) } \\
\hline University hospital & 49 & 35 & $0.124^{\mathrm{d}}$ & 0.022 & 75 & 9 & $0.77^{\mathrm{d}}$ & 0.229 \\
\hline Public hospital & 135 & 45 & & & 168 & 12 & & \\
\hline Private hospital or other & 161 & 68 & & & 217 & 12 & & \\
\hline \multicolumn{9}{|l|}{ 11. Basic charge for hospitalization } \\
\hline $\begin{array}{l}\text { Ratio of the number of patient to that } \\
\text { of nurses is not } 7: 1\end{array}$ & 87 & 25 & $0.091^{\mathrm{c}}$ & 0.043 & 111 & 1 & $0.126^{\mathrm{c}}$ & 0.002 \\
\hline $\begin{array}{l}\text { Ratio of the number of patient to that } \\
\text { of nurses is } 7: 1\end{array}$ & 258 & 123 & & & 349 & 32 & & \\
\hline \multicolumn{9}{|l|}{ 12. Presence of a role model } \\
\hline Lacking & 30 & 60 & $-0.378^{\mathrm{c}}$ & $<0.001$ & 74 & 16 & $-0.210^{\mathrm{c}}$ & $<0.001$ \\
\hline Present & 315 & 88 & & & 386 & 17 & & \\
\hline
\end{tabular}

a $1=$ the high-risk group, with total score of intention to leave in upper quartile; $0=$ low-risk group, with total score of intention to leave not in upper quartile

b 1 = "yes" group of female NGNs intending to resign from a current organization within this fiscal year (within 3 months); $0=$ "no" group of female NGNs not intending to resign from a current organization within this fiscal year (within 3 months)

${ }^{\mathrm{c}}$ Phi coefficient

${ }^{\mathrm{d}}$ Cramer's measure of association 
Table 3 Results of $t$ test for independent variables between two groups of each dependent variable $(n=493)$

\begin{tabular}{|c|c|c|c|c|c|c|}
\hline \multirow[t]{2}{*}{ Variable } & \multicolumn{3}{|l|}{ Indention to leave $\mathrm{a}^{\mathrm{a}}$} & \multicolumn{3}{|c|}{ Decision to resign $^{\mathrm{b}}$} \\
\hline & Low risk $(n=35)$ & High risk $(n=48)$ & $P$ value & No $(n=460)$ & Yes $(n=33)$ & $P$ value \\
\hline \multicolumn{7}{|l|}{ Individual factors } \\
\hline Being personally suited for nursing work & 8.07 & 5.92 & $<0.001$ & 7.50 & 6.33 & $<0.001$ \\
\hline GHQ-12 & 30.46 & 35.70 & $<0.001$ & 31.67 & 37.06 & $<0.001$ \\
\hline CF-13 & 25.19 & 31.16 & $<0.001$ & 26.69 & 31.00 & $<0.001$ \\
\hline \multicolumn{7}{|l|}{ Psychosocial factors in the work environment } \\
\hline Supervisor support & 8.15 & 6.56 & $<0.001$ & 7.79 & 6.06 & $<0.001$ \\
\hline Coworker support & 9.45 & 8.64 & $<0.001$ & 9.29 & 7.97 & $<0.001$ \\
\hline Quantitative demands & 62.42 & 74.08 & $<0.001$ & 65.42 & 72.94 & 0.009 \\
\hline Cognitive demands & 71.00 & 75.44 & 0.002 & 71.99 & 77.08 & 0.058 \\
\hline Emotional demands & 53.26 & 64.30 & $<0.001$ & 56.23 & 61.36 & 0.183 \\
\hline Demands for hiding emotions & 41.19 & 58.11 & $<0.001$ & 45.54 & 59.47 & $<0.001$ \\
\hline Sensory demands & 76.26 & 80.27 & 0.017 & 77.01 & 83.79 & 0.028 \\
\hline Presence of a role model & 0.91 & 0.59 & $<0.001$ & 0.84 & 0.52 & $<0.001$ \\
\hline
\end{tabular}

The mean comparisons of each group of dependent variables were assessed by $t$ test

a $1=$ high-risk group, with total score of intention to leave in upper quartile; $0=$ low-risk group, with total score of intention to leave not in upper quartile

b 1 = "yes" group of female NGNs intending to resign from a current organization within this fiscal year (within 3 months); $0=$ "no" group of female NGNs not intending to resign from a current organization within this fiscal year (within 3 months)

\section{Discussion}

The proportion of male nurses is approximately $5 \%$ in Japan [41]. With this in mind, nursing managers and supervisors should focus on female NGNs to prevent early resignation from their organizations. In this study, we examined individual factors (e.g., job readiness, psychological distress, cumulative fatigue) and factors in the work environment with regard to the intention to leave and the decision to resign among female NGNs in situations where hospital managers and supervisors could intervene. The findings of this study support the data that indicate NGNs intended to leave their job mostly because of negative work environment issues [28], though they stated a variety of other reasons when they actually resigned [6].

Our findings show that the factor pertaining to both the intention to leave and the decision to resign was the presence of a role model. Additionally, it should be noted that those who were not receiving a scholarship were more likely to resign from their current hospital $(\mathrm{OR}=3.238)$ than those who were receiving a scholarship. Although investment in human capital such as scholarships may have short-term benefits for the prevention of early resignation of female NGNs, our findings suggest that countermeasures from a mid- and long-term perspective (e.g., investment in human resources development) are needed to avert future potential resignations.

We found that support from supervisors had an important influence on the intention to leave among female
NGNs, a finding in line with other studies of NGNs [12, 13, 15]. Supervisors' management style has an effect on staff leaving their jobs, and managers' leadership is related to nurses' job stress [43]. These studies suggested that, from a long-term perspective, human resources development for preceptors and supervisors may contribute to the prevention of early resignation among NGNs.

The presence of a role model had a significant relationship with the intention to leave among NGNs [14]. We found that the lack of a role model influenced both the intention to leave and the decision to resign among female NGNs. A study of nursing students revealed that, in their view of career and work, the presence of a role model as well as a supportive work environment were important dimensions in continuing their future work as nurses [44]. Role models are expected to strive for self-improvement and to assertively help NGNs cope with difficult situations (e.g., incidents involving patients with critical illnesses).

Senior nurses in preceptorship represent the closest role models who can enhance NGNs' competence and clinical skills [37]. However, preceptors tend to be less assertive because of insufficient experience [45]. According to a survey of the Japanese Nursing Association, $85.6 \%$ of hospitals $(n=1,219)$ introduced preceptorship as part of NGNs' in-house training, with $60.2 \%$ of nurses who guide NGNs being in the first 3 years of having started their own career [28].

Moreover, in the present study female NGNs who perceived themselves as being personally suited for nursing 
Table 4 Multivariate logistic regression model for the upper quartile of intention to leave $(n=493)$

\begin{tabular}{|c|c|c|c|}
\hline & Odds ratio & $95 \%$ confidence interval & $P$ value \\
\hline \multicolumn{4}{|l|}{ Employment and organizational characteristics } \\
\hline Desirable position (in a word) ${ }^{\mathrm{a}}$ & 1.281 & $0.744-2.205$ & 0.372 \\
\hline Working more than $51 \mathrm{~h}$ per week ${ }^{\mathrm{b}}$ & 1.224 & $0.684-2.188$ & 0.496 \\
\hline Break facilities and amount of permitted rest time in the hospital ${ }^{c}$ & 1.464 & $0.831-2.581$ & 0.187 \\
\hline Hospital type (establishment) ${ }^{\mathrm{d}}$ & 1.796 & $0.999-3.229$ & 0.050 \\
\hline Basic charge for hospitalization $^{\mathrm{e}}$ & 1.476 & $0.717-3.038$ & 0.291 \\
\hline \multicolumn{4}{|l|}{ Individual factors } \\
\hline Being personally suited for nursing work ${ }^{\mathrm{f}}$ & 0.661 & $0.550-0.794$ & $<0.001$ \\
\hline GHQ-12 & 1.075 & $0.993-1.164$ & 0.076 \\
\hline $\mathrm{CF}-13^{\mathrm{f}}$ & 1.112 & $1.025-1.207$ & 0.011 \\
\hline \multicolumn{4}{|l|}{ Psychosocial factors in the work environment } \\
\hline Supervisor support ${ }^{\mathrm{f}}$ & 0.824 & $0.691-0.981$ & 0.030 \\
\hline Coworker support $^{\mathrm{f}}$ & 1.000 & $0.871-1.149$ & 0.994 \\
\hline Quantitative demands ${ }^{\mathrm{f}}$ & 1.017 & $0.993-1.042$ & 0.166 \\
\hline Cognitive demands ${ }^{f}$ & 1.001 & $0.975-1.028$ & 0.940 \\
\hline Emotional demands ${ }^{\mathrm{f}}$ & 0.989 & $0.973-1.006$ & 0.216 \\
\hline Demands for hiding emotions ${ }^{f}$ & 1.007 & 0.991-1.024 & 0.382 \\
\hline Sensory demands ${ }^{\mathrm{f}}$ & 1.001 & $0.979-1.023$ & 0.953 \\
\hline Presence of a role model ${ }^{\mathrm{g}}$ & 3.932 & $1.987-7.781$ & $<0.001$ \\
\hline
\end{tabular}

The result of the multivariate logistic regression analysis for independent variables (individual factors and psychosocial factors in the work environment) were entered into the equation, along with the variables of employment and organizational characteristics, using a stepwise method (backward selection method). Hosmer-Lemeshow goodness of fit $\chi^{2}=11.089, d f=8, P=0.196$

a $1=$ disagree, $0=$ agree

b $1=$ agree, $0=$ disagree

c 1 = inadequate break facilities and an insufficient amount of permitted rest time, $0=$ adequate break facilities and a sufficient amount of permitted rest time

d $1=$ not public hospital, $0=$ public hospital

e $1=$ ratio of the number of patients to that of nurses is 7:1,0 = ratio of the number of patients to that of nurses is not 7:1

${ }^{f}$ Continuous variable

g $1=$ lack of a role model, $0=$ presence of a role model

work showed significantly less intention to leave. This is consistent with the findings of male and female NGNs in advanced treatment hospitals [13-15] and suggests that such factors could influence decisions about resignation in the near future when female NGNs become mid-level staff nurses.

Therefore, regardless of their level of motivation in choosing nursing, it is necessary to provide NGNs with opportunities for internship to improve their job readiness before they begin work at hospitals. In addition, investment in human resources development for NGNs as well as preceptors and supervisors is needed not only for the prevention of early resignation among NGNs but also for the prevention of potential resignations from a mid- and longterm perspective.

Concerning subjective health status, we revealed that psychological distress was a risk factor of the decision to resign among female NGNs. Cumulative fatigue was a risk factor of NGNs' intention to leave. These findings suggest that hospital managers need to improve female NGNs' health status through human resources development (e.g., stress management) and workforce management.

Cumulative fatigue has a significant relationship with the intention to leave among NGNs [13-15]. While our findings support findings of earlier studies [13-15], cumulative fatigue was not an important factor regarding the decision to resign among female NGNs in the current study. However, turnover is related to nurses' exhaustion, and nurses with low levels of exhaustion are considered to have a health status compatible with continuing work [47]. Thus, cumulative fatigue may become a risk factor for future resignation among female NGNs when they become mid-level nurses because of exhaustion derived from cumulative fatigue.

The significance of psychological distress for the decision to resign among female NGNs in this study supports a 
Table 5 Multivariate logistic regression model for the decision to resign $(n=493)$

\begin{tabular}{|c|c|c|c|}
\hline Factor related to decision to resign & Odds ratio & $95 \%$ confidence interval & $P$ value \\
\hline \multicolumn{4}{|l|}{ Employment and organizational characteristics } \\
\hline Hospital scholarship ${ }^{a}$ & 3.238 & $1.075-9.752$ & 0.037 \\
\hline Break facilities and amount of permitted rest time in the hospital ${ }^{b}$ & 3.232 & $1.267-8.242$ & 0.014 \\
\hline Basic charge for hospitalization $^{c}$ & 7.367 & $0.920-58.964$ & 0.060 \\
\hline \multicolumn{4}{|l|}{ Individual factors } \\
\hline Being personally suited for nursing work ${ }^{\mathrm{d}}$ & 1.074 & $0.826-1.397$ & 0.592 \\
\hline GHQ-12 ${ }^{\mathrm{d}}$ & 1.175 & $1.043-1.324$ & 0.008 \\
\hline $\mathrm{CF}-13^{\mathrm{d}}$ & 1.020 & $0.904-1.151$ & 0.752 \\
\hline \multicolumn{4}{|l|}{ Psychosocial factors in the work environment } \\
\hline Supervisor support $^{\mathrm{d}}$ & 0.851 & $0.655-1.106$ & 0.228 \\
\hline Coworker support $^{\mathrm{d}}$ & 0.860 & $0.711-1.041$ & 0.122 \\
\hline Quantitative demands ${ }^{\mathrm{d}}$ & 0.989 & $0.957-1.023$ & 0.521 \\
\hline Cognitive demands ${ }^{\mathrm{d}}$ & 0.995 & $0.956-1.035$ & 0.802 \\
\hline Emotional demands ${ }^{\mathrm{d}}$ & 0.989 & $0.966-1.013$ & 0.358 \\
\hline Demands for hiding emotions ${ }^{\mathrm{d}}$ & 1.004 & $0.979-1.029$ & 0.751 \\
\hline Sensory demands ${ }^{\mathrm{d}}$ & 1.023 & $0.986-1.061$ & 0.228 \\
\hline Presence of a role model ${ }^{\mathrm{e}}$ & 2.794 & $1.117-6.989$ & 0.028 \\
\hline
\end{tabular}

The result of the multivariate logistic regression analysis for independent variables (individual factors and psychosocial factors in the work environment) were entered into equation, along with the variables of employment and organizational characteristics, using a stepwise method (backward selection method). Hosmer-Lemeshow goodness of fit: $\chi^{2}=4.615, d f=8, P=0.797$

a $1=$ not received, $0=$ received

b $1=$ inadequate break facilities and an insufficient amount of permitted rest time, $0=$ adequate break facilities and a sufficient amount of permitted rest time

c $1=$ ratio of the number of patients to that of nurses is 7:1,0 = ratio of the number of patients to that of nurses is not 7:1

d Continuous variable

e $1=$ lack of a role model, $0=$ presence of a role model

previous survey of hospitals $(n=1,219)$ in Japan which revealed "early resignation by NGNs due to psychological health problems will increase in the near future" [28]. In a group of new recruits within the same medical institution in Japan, NGNs had lower psychological health and were more stressed about job requirements than medical doctors who were in the first year of their career [46]. Thus, in order to prevent NGNs' early resignation, health management that focuses on the psychological health problems of NGNs is required.

Inadequate break facilities and an insufficient amount of permitted rest time also showed positive correlation coefficients with cumulative fatigue of NGNs [15]. In this study, NGNs who thought break facilities and amount of permitted rest time in the hospital were inadequate were more likely to resign from their current hospital than those who thought break facilities and amount of permitted rest time in the hospital were adequate $(\mathrm{OR}=3.232)$. This shows that adequate break facilities and a sufficient amount of permitted rest time as well as assessment of individual workload are important for the prevention of early resignation among female NGNs.
A previous study using the COPSOQ $(n=1,858)$ revealed that, out of 32 jobs, healthcare professionals (e.g., nurse, nurse's aide) perceived the highest emotional demands [33]. Another study of registered female nurses in China $(n=3,088)$ using the COPSOQ revealed that increased emotional demands and decreased meaning of work were associated with the intention to leave [22]. However, in the present study's findings, the COPSOQ subscales were not significantly related to either outcome.

The inconsistency related to psychological job demands in the work environment may be due to different responses to stressful experiences (i.e., emotional labor) of nurses as found in other studies compared with the female NGNs in this study. Emotional labor is defined as the process of regulating experienced and displayed emotions to present a professionally desired image during interpersonal transactions at work [20]. It is also a process whereby nurses adopt a "work persona" to express their autonomous emotions during patient encounters [48].

Another study using an assessment tool for emotional demands derived from emotional labor [49] revealed that emotional demands have an effect on job-related stress 
among nurses. This suggests that, even if nurses recognize that their true feelings toward patients and the clinical environment are different from what are appropriate, being told to adjust their feelings may be stressful for nurses [49, 50]. Our finding that emotional demands did not influence female NGNs' intention to leave or decision to resign may be the result of our subjects' inexperience, as they had not been working long enough to adopt an appropriate "work persona" [48].

However, we found that psychological factors of the work environment were not significantly associated with either female NGNs' intention to leave or decision to resign. This is despite psychological factors in the work environment having been shown to be significantly associated with NGNs' turnover and the intention to leave [8-10, 13-15]. Since there have been no studies examining the effect of factors assessed by the COPSOQ on NGNs' intention to leave and the decision to resign except for this study, further studies are needed to examine the effect of psychological factors in the work environment using the COPSOQ.

\section{Limitations of this study}

This study has some limitations that should be discussed. First, the response rate was relatively low (41\%). Second, although the intention to leave is consistently the best predictor of actual employee turnover [7, 11], it does not coincide with turnover [12]. Additionally, because the decision to resign in this study was based on data collected during the last 3 months of the fiscal year when the participants were employed, the data were reliable for turnover [40]. Since this study used a cross-sectional design, longitudinal surveys are needed to examine the factors related to the intention to leave and the decision to resign among NGNs, as well as to examine turnover in a nearfuture time frame. Third, this study did not examine factors of support systems for work-life balance (e.g., marriage, having a baby, and raising children) for female employees because only $8 \%$ of NGNs in this study were married females. Considering the fact that, of all reasons for early resignation among NGNs, reasons of marriage and having a baby and raising children accounted for $12 \%$ and educational advancement accounted for $23 \%$ [6], further studies are encouraged to examine factors in support systems for work-life balance as well as career building. Fourth, the reliability and validity of the COPSOQ should be verified in future studies. Finally, because the dependent variables were based on self-reported data, future studies should use more objective measures.

Despite these limitations, most of the previously published studies of the intention to leave and turnover among NGNs in Japan examined NGNs in large advanced treatment hospitals or university hospitals with more than 500 beds [9, 10, 13-15]. No study examined factors related to both the intention to leave and the decision to resign among female NGNs. Therefore, our findings of a complete survey with a large sample do provide meaningful new insights. These can help hospital managers and supervisors in their organization find ways for possible countermeasures against the shortage of nurses.

\section{Conclusions}

This study examined factors related to the intention to leave and the decision to resign among female NGNs, including individual and psychosocial factors in the work environment. The results are summarized as follows:

1. The factor pertaining to both the upper quartile of the intention to leave and the decision to resign was the lack of a role model. Additionally, support from supervisors and job readiness (being personally suited for nursing work) showed significant relationships with the upper quartile of the intention to leave.

2. The female NGNs who were not receiving a hospital scholarship were more likely to resign from a current hospital than those who were receiving a hospital scholarship.

3. Psychological distress was a risk factor of the decision to resign. Other factors of similar importance were inadequate break facilities and an insufficient amount of permitted rest time. Cumulative fatigue was a risk factor of the intention to leave among female NGNs.

These findings suggest that, while investment in human capital, such as scholarships, may have short-term benefits for the prevention of early resignation among NGNs, countermeasures from a mid- and long-term perspective (e.g., investment in human resources development for all nurses, stress management to improve their psychological health problems, measurements of cumulative fatigue through assessments of workload along with provision of adequate break facilities and sufficient amounts of permitted rest time) are needed to avert potential resignations.

Acknowledgments The author expresses her thanks to all participants and hospitals in $\mathrm{H}$ prefecture. This study was supported by a research grant from St. Luke's Life Science Institute in 2009.

Conflict of interest None.

\section{References}

1. Health Labour and Welfare Statistics Association. The second section major index of hygiene: trend of population. In: Journal of health and welfare statistics. Tokyo: Okumura Printing Company; 2011. p. 39-69 (article in Japanese). 
2. Ministry of Health Labour and Welfare. The seventh result of the study concerning the supply-demand outlook of nursing staff. In: July 16th, editor. Tokyo: Ministry of Health, Labor \& Welfare, Health Policy Bureau; 2010. p. 1-2 (article in Japanese).

3. Cho J, Laschinger HK, Wong C. Workplace empowerment, work engagement and organizational commitment of new graduate nurses. Nurs Leadersh (Tor Ont). 2006;19:43-60.

4. VHA I. VHA's 2002 research series: the business case for workforce stability. http://www.healthleadersmedia.com/pdf/white_ papers/wp_vha_120103.pdf.(2002). Accessed 2nd March 2012.

5. Hayes JH, Scott AS. Mentoring partnerships as the wave of the future for new graduates. Nurs Educ Perspect. 2007;28:27-9.

6. Japanese Nursing Association Nurse Center. Report of countermeasures for the early retirement of newly graduated nurses in 2005. Tokyo: Japanese Nursing Association Nurse Center; 2006. p. 1-33 (article in Japanese).

7. MorBark E, Nissly JA, Levin A. Antecedents to retention and turnover among child welfare, social work, and other human service employees: what can we learn from past research? A review and meta-analysis. Soc Serv Rev. 2001;75:625-61.

8. Bowles C, Candela L. First job experiences of recent RN graduates: improving the work environment. J Nurs Adm. 2005;35: 130-7.

9. Suzuki E, Itomine I, Kanoya Y, Katsuki T, Horii S, Sato C. Factors affecting rapid turnover of novice nurses in university hospitals. J Occup Health. 2006;48:49-61.

10. Suzuki E, Itomine I, Saito M, Katsuki T, Sato C. Factors affecting the turnover of novice nurses at university hospitals: a two year longitudinal study. Jpn J Nurs Sci. 2008;5:9-21.

11. Mobley WH. Employee turnover: causes, consequences, and control. Boston: Addison-Wesley; 1982. p. 1-205.

12. Beecroft PC, Dorey F, Wenten M. Turnover intention in new graduate nurses: a multivariate analysis. J Adv Nurs. 2008;62: $41-52$.

13. Tei-Tominaga M, Miki A. A longitudinal study of factors associated with intentions to leave among newly graduated nurses in eight advanced treatment hospitals in Japan. Ind Health. 2010;48: 305-16.

14. Tei-Tominaga M, Miki A. Factors associated with intention to leave among newly graduated nurses in advanced treatment hospitals in Japan. Jpn J Nurs Sci. 2011;8:33-46.

15. Tei-Tominaga M, Miki A, Fujimura K. A cross-sectional study of factors associated with intentions to leave among newly graduated nurses in eight advanced treatment hospitals: job stressors, job readiness, and subjective health status. Nippon Koshu Eisei Zasshi. 2009;56:301-11.

16. Karasek R, Theorell T. Healthy work: stress, productivity, and the reconstruction of working life. New York: Basic Book; 1990. p. 1-346.

17. Siegrist J. Adverse health effects of high-effort/low-reward conditions. J Occup Health Psychol. 1996;1:27-41.

18. de Jonge J, Mulder MJ, Nijhuis FJ. The incorporation of different demand concepts in the job demand-control model: effects on health care professionals. Soc Sci Med. 1999;48:1149-60.

19. Tsutsumi A, Kawakami N. A review of empirical studies on the model of effort-reward imbalance at work: reducing occupational stress by implementing a new theory. Soc Sci Med. 2004;59: 2335-59.

20. Hochschild A. The managed heart: commercialization of human feeling. Berkeley: University of California Press; 1983. p. 1-320.

21. Larson EB, Yao X. Clinical empathy as emotional labor in the patientphysician relationship. J Am Med Assoc (JAMA). 2005;293:1100-6.

22. Li J, Fu H, Hu Y, Shang L, Wu Y, Kristensen TS, et al. Psychosocial work environment and intention to leave the nursing profession: results from the longitudinal Chinese NEXT study... Nurses' Early eXit sTudy. Scand J Public Health. 2010;38:69-80.
23. Japanese Nursing Association. News release 16 March in 2010. Japanese Nursing Association. http://www.nurse.or.jp/home/ opinion/press/2009pdf/0316sanko-2.pdf (2010). Accessed 2nd March 2012 (article in Japanese).

24. Japanese Nursing Association. News release 16 June in 2009. Japanese Nursing Association. http://www.nurse.or.jp/home/opinion/ newsrelease/2009pdf/20090616-1.pdf (2009). Accessed 2nd March 2012 (article in Japanese).

25. Peter R, Alfredsson L, Hammar N, Siegrist J, Theorell T, Westerholm P. High effort, low reward, and cardiovascular risk factors in employed Swedish men and women: baseline results from the WOLF Study. J Epidemiol Commun Health. 1998;52:540-7.

26. Hoeymans N, Garssen AA, Westert GP, Verhaak PF. Measuring mental health of the Dutch population: a comparison of the GHQ12 and the MHI-5. Health Qual Life Outcomes. 2004;2:23.

27. Kurata T, Tajima M, Hamano I, Ueyama E. Byouin taiyo no shougakukin wo kangaeyou. (Think about scholarship loan in hospitals). Byouin. 1993;52:820-4.

28. Japanese Nursing Association Nurse Center. Survey report of the actual condition of early retirement among newly graduated nurses in 2004. Tokyo: Japanese Nursing Association Nurse Center; 2005. p. 1-93 (article in Japanese).

29. Goldberg DP, Gater R, Sartorius N, Ustun TB, Piccinelli M, Gureje $\mathrm{O}$, et al. The validity of two versions of the GHQ in the WHO study of mental illness in general health care. Psychol Med. 1997;27:191-7.

30. Ministry of Health LaW. Roudosya-no hirouchikusekido checklist (Check list for assessing cumulative fatigue of worker). In: Ministry of Health LaW, editor. Tokyo: Ministry of Health, Labour and Welfare; 2004.

31. Kristensen TS, Bjorner JB, Christensen KB, Borg V. The distinction between work pace and working hours in the measurement of quantitative demands at work. Work Stress. 2004;18: 305-22.

32. Miki A, Kawakami N, Tsutsumi A, Kondo K, Kawaguchi S. The reliability and validity of the Japanese version of Copenhagen Psychosocial Questionnaire. Sangyo Eiseigaku Zasshi. 2005;47 Suppl:631 (article in Japanese).

33. Kristensen T, Hannerz H, Høgh A, Borg V. The Copenhagen Psychosocial Questionnaire-a tool for the assessment and improvement of the psychosocial work environment. Scand J Work Environ Health. 2005;31:438-49.

34. Lavoie-Tremblay M, O’Brien-Pallas L, Gelinas C, Desforges N, Marchionni C. Addressing the turnover issue among new nurses from a generational viewpoint. J Nurs Manag. 2008;16:724-33.

35. Shimomitsu T, Yokoyama K, Ona Y, Maruta T, Tanigawa T, Haratani T, et al. Syokuba niokeru sutoresusokutei notameno kanbenna tyousahyouno sakusei. (development of a novel brief job stress questionnaire). In: Kato M, editor. Roudousyo Heisei 9 nendo Sagyokanrenshikkanno yoboni kansuru kenkyu (Ministry of Labor's 1998 annual report, studies for prevention of workrelated diseases). Tokyo: Tokyo Medical University; 1998 (article in Japanese).

36. Shimomitsu T, Haratani T. Syokugyousei sutoresu kanityousahyouno shinraiseino kentouto kijyunnchino settei. (A study of reliability and standard value for convenient questionnaire of work stress.). In: Kato M, editor. Roudousyo Heisei 11 nendo Sagyokanrenshikkanno yoboni kansuru kenkyu (Ministry of Labor's 2000 annual report, studies for prevention of workrelated diseases) Tokyo: Tokyo Medical University; 2000. p. 126-38 (article in Japanese).

37. Kelly D, Simpson S, Brown P. An action research project to evaluate the clinical practice facilitator role for junior nurses in an acute hospital setting. J Clin Nurs. 2002;11:90-8.

38. Tei M, Yamazaki Y. The effect of work and organizational characteristics on individual and organizational outcomes of an 
information service company. San Ei Shi. 2003;45:20-30 (article in Japanese with English abstract).

39. Tei M, Yamazaki Y. The effect of work and organizational characteristics on workers in call centers: longitudinal study in an information service company. San Ei Shi. 2005;47:210-23. (article in Japanese with English abstract).

40. Hasselhorn HM, Tackenberg P, Kuemmerling A, Wittenberg J, Simon M, Conway PM, et al. Nurses' health, age and the wish to leave the profession-findings from the European NEXT-study. Med Lav. 2006;97:207-14.

41. Ministry of Health Labour and Welfare. A report of public administration of health and hygiene in 2006. Ministry of Health Labour and Welfare. http://www.mhlw.go.jp/toukei/saikin/hw/ eisei/06/kekka1.html (2006). Accessed 8nd June 2012 (article in Japanese).

42. Masuda N, Tahara Y, Shimada M, Takahashi T, Kitashiro N, Igarashi K. Determinant factors of place of employment for students in nursing college: an attitude survey of nursing colleges in a prefecture. Nihon Kangogakkai Ronbunsyu Kangokanri. 2010;41:75-8.

43. Coomber B, Barriball KL. Impact of job satisfaction components on intent to leave and turnover for hospital-based nurse: a review of the research literature. Int J Nurs Stud. 2007;44:297-314.

44. Shibuya K, Mikami T. Study on the prevention of newly graduate nursing personnel from resigning at an early stage: with an analysis of nursing students' hopes regarding the workplace and preceptors. Bull Nayoro City Univ. 2007;1:23-9. (article in Japanese with English abstract).

45. Tamai Y, Kageyama T, Maeda H. Self-expression attitude of senior nurses toward novice nurses from the aspect of assertion theory. Jpn J Ment Health. 2007;22:66-79. (article in Japanese with English abstract).

46. Matsumoto H, Ikeda S, Mori M. A study of factors related to mental health and work stress among medical doctors and nurses within the same medical institution. Hokkaido J Public Health. 2002;15:155-65. (article in Japanese).

47. Shimizu T, Feng Q, Nagata S. Relationship between turnover and burnout among Japanese hospital nurses. J Occup Health. 2005;41:334-6.

48. Huynh T, Alderson M, Thompson M. Emotional labour underlying caring: an evolutionary concept analysis. J Adv Nurs. 2008;64:195-208.

49. Katayama Y, Ogasawara C, Tsuji C, Imura K, Nagayama H. Development of Emotional Labor Inventory for Nurses. Nihon Kango Kagaku Kai Shi. 2005;25:20-7. (article in Japanese).

50. Katayama H. Relationship between emotional labor and jobrelated stress among hospital nurses. Jpn J Hyg. 2010;65:524-9. (article in Japanese with English abstract). 